\title{
Value transfer in concurrent-schedule discriminations by pigeons
}

\author{
THOMAS R. ZENTALL, JANICE E. WEAVER, and LOU M. SHERBURNE \\ University of Kentucky, Lexington, Kentucky
}

\begin{abstract}
When pigeons are trained on a discrete-trial simultaneous discrimination, some of the value associated with the positive stimulus appears to transfer to the negative stimulus (Zentall \& Sherburne, 1994). Pigeons preferred a negative stimulus that had been discriminated from an always-positive stimulus $(\mathbf{S}+)$ over a negative stimulus that had been discriminated from a sometimes-positive stimulus $(\mathbf{S} \pm$ ). A very different finding (suggestive of transitivity of preference or contrast) was reported by Belke (1992). On concurrent probe tests of stimuli associated with equal variable interval (VI) schedules but originally trained in alternative concurrent pairs (one with a richer schedule, the other with a poorer schedule-VI $20 \mathrm{sec}$ vs. VI $40 \mathrm{sec}$ and VI $40 \mathrm{sec}$ vs. VI $80 \mathrm{sec}$ ), the stimulus originally paired with the poorer schedule was preferred. But Belke's results may have been obtained because the pigeons had been trained to peck the VI $40 \mathrm{sec}$ paired with the poorer schedule and they had been trained not to peck the VI $40 \mathrm{sec}$ paired with the richer schedule. In the present experiment, we avoided this bias by training pigeons on two concurrent schedules in which the tested stimuli both had been associated with the poorer schedule of the pair [A(VI $20 \mathrm{sec}$ ) vs. B(VI $80 \mathrm{sec})$ and C(VI $40 \mathrm{sec}$ ) vs. D(VI $80 \mathrm{sec})$ ]. Evidence for value transfer was demonstrated when on probe trials pigeons preferred $B$ over $D$.
\end{abstract}

In traditional theories of discrimination learning, interactions between the two stimuli involved in a simple discrimination ( + , to which responses are reinforced and $\mathrm{S}-$, to which responses are not reinforced) have been interpreted primarily in terms of their physical similarity to each other (see, e.g., Hearst, 1968; Logan, 1966; Spence, 1937). For example, if a discrimination involves two very similar stimuli, the generalization of excitation resulting from reinforced responding to the $\mathrm{S}+$ may generalize to the $\mathrm{S}-$, making it very difficult for an organism to inhibit responding to the $\mathrm{S}-$. Furthermore, what interaction does occur between the $S+$ and $S-$ in a discrimination has been interpreted independently of the temporal relation between the two stimuli (i.e., whether they are presented simultaneously or successively). Recently, it has been suggested that during simultaneous discrimination training, some of the excitation or response strength acquired by the $S+$ transfers to the $S-$, independent of the physical similarity between the S+ and S- (Fersen, Wynne, Delius, \& Staddon, 1991). This theory of transferred response strength, known as value transfer theory, has received empirical support (Steirn, Weaver, \& Zentall, 1995; Zentall \& Sherburne, 1994; Zentall, Sherburne, Roper, \& Kraemer, 1996). For example, Zentall and Sherburne trained pigeons on two simultaneous discriminations, one in which responses to one of the stimuli were always reinforced and responses to the other were never rein-

This research was supported by National Science Foundation Grants BNS-9019080 and IBN-9414589, and National Institute of Mental Health Grant 45979 to T.R.Z. Correspondence should be addressed to T. R. Zentall, Department of Psychology, University of Kentucky, Lexington, KY 40506 (e-mail: zentall@pop.uky.edu). forced $(\mathrm{A}+\mathrm{B}-)$, and the other in which responses to one of the stimuli were reinforced on only half of the trials and responses to the other stimulus were never reinforced $(\mathrm{C} \pm \mathrm{D}-)$. On probe trials involving the two negative stimuli (B and D), pigeons preferred the stimulus that was presented in training with the more positive training stimulus (A rather than $\mathrm{C}$ ).

These results would appear to be inconsistent with more typically reported behavioral contrast effects, in which responding to a stimulus is affected not only by the schedule of reinforcement associated with that stimulus, but also in contrast to schedules associated with other stimuli that are also experienced in that context (see, e.g., Reynolds, 1961). There is typically more responding to a stimulus associated with a particular schedule of reinforcement if that stimulus is presented in the context of a poorer schedule (positive behavioral contrast), and there is typically less responding to that stimulus if it is presented in the context of a richer schedule (negative behavioral contrast, Guttman, Sutterer, \& Brush, 1975). Zentall and Sherburne (1994) have suggested that procedural differences can account for these opposite effects (i.e., contrast vs. value transfer). They proposed that when training involves successive discriminations, contrast effects will occur, whereas when training involves simultaneous discriminations, value transfer will occur.

Belke (1992; see also Gibbon, 1995) has recently reported findings that would appear to be inconsistent with Zentall and Sherburne's (1994) hypothesis. Belke trained pigeons on two simultaneous (concurrent schedules) discriminations involving variable interval (VI) schedules of reinforcement. In a VI schedule, reinforcement is provided for the first response after a variable duration (e.g., 
$20 \mathrm{sec})$. On some trials, the pigeons in Belke's experiment had a choice between a stimulus associated with a relatively rich schedule and one associated with a moderate schedule [A(VI $20 \mathrm{sec}$ ) vs. B(VI $40 \mathrm{sec}$ )]. On other trials, they had a choice between a stimulus associated with a moderate schedule and one associated with a relatively poor schedule [C(VI $40 \mathrm{sec})$ vs. D(VI $80 \mathrm{sec})]$. On probe trials involving presentation of $B$ versus $C$ (two stimuli associated with the same schedule of reinforcement), the pigeons consistently chose $\mathrm{C}$ over $\mathrm{B}$. The design of Belke's experiment is shown in Table 1.

Two accounts can be given for the difference between the results found by Belke (1992) and those reported by Zentall and Sherburne (1994). On the one hand, it may be that value transfer does not occur under the conditions (concurrent schedules) used by Belke. Zentall et al. (1996) have proposed that the mechanism underlying value transfer is Pavlovian in nature and that a within-event association develops between the $\mathrm{S}+$ and $\mathrm{S}-$ in a discrete-trial simultaneous discrimination. According to this hypothesis, the $\mathrm{S}+/ \mathrm{S}-$ presentation can be thought of as a compound, which is then associated with the unconditioned stimulus (US, food). If this view is correct, Belke's freeoperant procedure may not encourage the within-event Pavlovian processes that are proposed to occur in the discrete-trial procedure. The free-operant procedure may not be ideal for producing within-event conditioning for three reasons: First, the temporal contiguity between the onset of the CS and US is not as well defined in the freeoperant procedure (typically the CS is present both prior to and following the US). Second, when concurrent schedules are used, reinforcement is typically associated with responding to both stimuli, whereas in the discretetrial simultaneous discrimination procedure that has been used to test value transfer theory, responding to one of the two stimuli in the discrimination is typically extinguished. (Although nothing inherent in value transfer theory requires that the poorer schedules be extinction, value transfer has not yet been tested with other schedules.) Third, when concurrent schedules are used, it is difficult to specify the nature of the association formed because one cannot easily specify the pattern of responding (i.e., the distribution of number of pecking bouts and their duration) to the two concurrently presented stimuli prior to each reinforcement.

On the other hand, it may not be the free-operant procedure that obscured the effects of value transfer in Belke's (1992) experiment but rather, the experimental design that was used. Whereas in Zentall and Sherburne's (1994) experiments, probe trials involved a choice between the stimuli that were associated in training with the two poorest schedules (B - vs. D-), in Belke's experiment, probe trials involved a choice between the poorer schedule from one discrimination [B(VI $40 \mathrm{sec})$, which had, in training, been presented in the context of A(VI $20 \mathrm{sec})]$ and the richer schedule from the other discrimination [C(VI $40 \mathrm{sec})$, which had, in training, been presented in the context of $D$ (VI $80 \mathrm{sec})]$. Thus, a potential problem with Belke's design is that in training, the pigeons had learned to peck C (VI $40 \mathrm{sec})$ more than the stimulus with which it had been presented, and to peck B(VI $40 \mathrm{sec}$ ) less than the stimulus with which it had been presented. Consequently, during training, different response patterns were established to the two probe stimuli, and those trained differences could account for the preference for C over B on probe trials (see also Williams, 1994, for a similar analysis of Belke's findings).

The purpose of the present experiment was to determine whether value transfer could be demonstrated with a concurrent schedules procedure of the sort used by Belke (1992) if Zentall and Sherburne's (1994) design were used. In the present experiment, pigeons were trained on two concurrent discriminations, as were Belke's pigeons, but probe trials involved a choice between the stimuli associated with the poorer schedule from each discrimination experienced in training. The design of the present experiment is shown in Table 1. Predicted results based on three theories of discrimination learning appear in Table 2.

According to traditional theories of discrimination learning, similar schedules should not result in a preference for either schedule, so no preference should be found on probe trials. According to Belke's (1992) transitivity of preference (or contrast) hypothesis, there should be a preference for the stimulus (D) that was presented in training with the stimulus associated with the poorer schedule (C). According to value transfer theory, however, the stimulus that was paired in training with the stimulus associated with the richer schedule should be preferred because more value should transfer from the richer schedule A(VI $20 \mathrm{sec}$ ) to B than from the poorer schedule C(VI $40 \mathrm{sec})$ to $\mathrm{D}$.

Following the first test, a second test was conducted involving a choice between the stimuli associated with the richer schedule from each discrimination experienced during training. The second test served primarily as

Table 1

Designs of Belke's (1992) Experiment and the Present Experiment

\begin{tabular}{|c|c|c|}
\hline \multicolumn{2}{|r|}{ Belke (1992) } & Present Experiment \\
\hline Train: & $\begin{array}{l}\text { Two concurrent schedules } \\
\text { [A(VI } 20 \mathrm{sec}) \text { vs. B(VI } 40 \mathrm{sec})] \text { and } \\
[\mathrm{C}(\mathrm{VI} 40 \mathrm{sec}) \text { vs. D(VI } 80 \mathrm{sec})]\end{array}$ & $\begin{array}{l}\text { Two concurrent schedules } \\
\text { [A(VI } 20 \mathrm{sec}) \text { vs. B(VI } 80 \mathrm{sec})] \text { and } \\
\text { [C(VI } 40 \mathrm{sec}) \text { vs. D(VI } 80 \mathrm{sec})]\end{array}$ \\
\hline Test: & $\mathrm{B}(\mathrm{VI} 40 \mathrm{sec})$ vs. $\mathrm{C}(\mathrm{VI} 40 \mathrm{sec})$ & B(VI $80 \mathrm{sec})$ vs. D(VI $80 \mathrm{sec})$ \\
\hline
\end{tabular}

Note-VI, variable interval. 
Table 2

Predicted Outcomes by Three Theories of Discrimination Learning Following Training With Two Pairs of Concurrent Schedules

\begin{tabular}{|c|c|c|}
\hline Theory & Probe Test B versus D & Rationale \\
\hline $\begin{array}{l}\text { Reinforcement } \\
\text { history }\end{array}$ & Indifference & $\begin{array}{l}\text { Excitation associated with } A \text { and } C \\
\text { should have minimal effect on } B \text { and } D \text {. }\end{array}$ \\
\hline $\begin{array}{l}\text { Behavioral } \\
\text { contrast }\end{array}$ & Preference for D & $\begin{array}{l}\text { There should be greater contrast } \\
\text { between } B \text { and the rich schedule A than } \\
\text { between } D \text { and the less rich schedule } C \text {. }\end{array}$ \\
\hline $\begin{array}{l}\text { Value } \\
\text { transfer }\end{array}$ & Preference for B & $\begin{array}{l}\text { More value should transfer from the richer } \\
\text { schedule } A \text { to } B \text { than from the less rich } \\
\text { schedule } C \text { to } D \text {. }\end{array}$ \\
\hline
\end{tabular}

Note-A(VI $20 \mathrm{sec})$ versus $B(V I 80 \mathrm{sec})$ and C (VI $40 \mathrm{sec})$ versus $D(V I 80 \mathrm{sec})$, on probe-trial tests involving B(VI $80 \mathrm{sec})$ versus D(VI $80 \mathrm{sec})$.

a manipulation check to determine if the absolute value of the relatively richer schedule makes a difference (i.e., to determine if the stimulus associated with the VI $20 \mathrm{sec}$ schedule from one discrimination is preferred over the stimulus associated with the VI $40 \mathrm{sec}$ schedule from the other discrimination).

A second purpose of the present experiment was to attempt to replicate a finding by Zentall et al. (1996) related to the nature of the associations established during original training. Zentall et al. argued that if the stimulus associated with the poorer schedule obtained its extra value indirectly, by signaling the presence of the richer schedule (second-order Pavlovian conditioning), one should be able to show evidence of that association by devaluing the richer schedule (in the absence of the poorer schedule) and then finding that the poorer schedule lost value as well (i.e., it was less preferred).

Alternatively, the stimulus associated with the poorer schedule could obtain its extra value directly, through trace conditioning. To the extent that observation of the stimulus associated with the poorer schedule occurred shortly before a reinforced peck to the stimulus associated with the richer schedule, direct Pavlovian conditioning of the stimulus associated with the poorer schedule is possible. If the extra value acquired by the stimulus associated with the poorer schedule is directly obtained, then devaluation of the richer schedule should have little effect on the stimulus associated with the poorer schedule. A diagram of these two conditioning mechanisms appears in Figure 1.

Zentall et al. (1996, Experiment 1) found that the devaluation of the richer schedule eliminated the preference for the poorer schedule with which it had been presented. Thus, their results support a second-order condition account of value transfer, and they suggest that a similar effect might be found in the present experiment.

To assess the effects of devaluation in the present experiment, we divided the pigeons into two groups. For one group, responses were extinguished to the stimulus associated with the richer schedule from one discrimination. For the other group, responses were extinguished to the stimulus associated with the richer schedule from the other discrimination. Pigeons from both groups were then retested with the stimuli associated with the poorer schedule from each discrimination. If value transfer occurs because the stimulus associated with the poorer schedule signals the presence of the stimulus associated with the richer schedule, devaluation of the stimulus associated with the richer schedule should reduce the preference for the poorer schedule, and this shift in preference should occur in opposite directions for the two extinction groups. If, however, value transfer involves a direct conditioning

$$
\begin{aligned}
& \text { (1) Higher order } \operatorname{CS} 2[B(V \mid 80 \text { sec })]==>\operatorname{CS} 1[A(V \mid 20 \text { sec })]==>\text { US } \\
& \text { conditioning: } \\
& \text { (2) Direct } \\
& \operatorname{CS} 2[\mathrm{~B}(\mathrm{~V} \mid 80 \mathrm{sec})]=============>\text { US } \\
& \text { conditioning: } \\
& \operatorname{CS1}[\mathrm{A}(\mathrm{V} \mid 20 \mathrm{sec})]=====>\text { US }
\end{aligned}
$$

Figure 1. Two possible bases for an association between a negative stimulus and a positive stimulus in a simultaneous discrimination. Note- $C S$, conditioned stimulus; US, unconditioned stimulus; VI, variable interval. 
process, probe-trial preferences should not differ for the two groups.

\section{METHOD}

\section{Subjects}

The subjects were eight White Carneaux pigeons (retired breeders, 5-8 years old) purchased from the Palmetto Pigeon Plant (Sumter, SC). Previously, the pigeons had been trained on a hue matching-to-sample task involving red, green, blue, and yellow hues. The pigeons were housed in individual wire cages and were maintained at $80 \%$ of their free-feeding weights throughout the experiment. They had free access to water and grit. The colony room in which the pigeons were housed was maintained on a 12:12-h light:dark cycle.

\section{Apparatus}

The experiment was conducted in a sound-attenuated test chamber that measured $37 \mathrm{~cm}$ high, $34 \mathrm{~cm}$ across the response panel, and $30 \mathrm{~cm}$ from the response panel to the back wall. Centrally mounted side by side on the response panel were three pecking keys $(3.2 \mathrm{~cm}$ wide $\times 2.5 \mathrm{~cm}$ high and $0.5 \mathrm{~cm}$ apart). The bottom edges of the pecking keys were $16.0 \mathrm{~cm}$ from the wire mesh floor of the chamber. Only the left and right pecking keys were used in the present experiment. Behind each pecking key was a 12-stimulus in-line projector (Model 10, Industrial Electronics Engineering, Van Nuys, CA) with 28-V, 0.1-A lamps that projected one of four hues-red (R), green $(\mathrm{G})$, yellow $(\mathrm{Y})$, or blue (B) (produced by Wratten filters, Nos. 26, 60, 9, and 38a, respectively) - onto each of the response keys.

The opening to a rear-mounted grain feeder was centered on the response panel midway between the floor and the pecking keys. Reinforcement for correct responding consisted of timed access to Purina Pro Grains. A shielded houselight (GE 1820) located $7.6 \mathrm{~cm}$ above the center pecking key provided general chamber illumination. White noise at $72 \mathrm{~dB}$ and an exhaust fan mounted on the outside of the chamber provided sound masking. The experiment was controlled from an adjacent room by a microcomputer.

\section{Procedure}

Pretraining. All pigeons were given "reminder" training to eat from the grain feeder and peck at each of the four hues (R, G, Y, $B)$ randomly presented on each of the side pecking keys. Each peck produced $3 \mathrm{sec}$ of reinforcement, followed by $10 \mathrm{sec}$ before the onset of the next stimulus. The hue or position of the stimulus changed following each reinforcement. On the next 3 days of pretraining, the number of responses required for reinforcement was increased first to 5 , then to 10 , and finally to 20 .

Discrimination training. Simultaneous discrimination training began the next day. The four pretraining stimuli were divided into two pairs, RY and GB. Each training trial began with the onset of one pair of stimuli (one on the left, the other on the right pecking key). In the presence of one pair of stimuli, a VI $20 \mathrm{sec}$ schedule was in effect for responses to one of the stimuli (A), and a VI $80 \mathrm{sec}$ schedule was in effect for responses to the other (B). In the presence of the other pair of stimuli, a VI 40 sec schedule was in effect for responses to one of the stimuli (C), and a VI $80 \mathrm{sec}$ schedule was in effect for responses to the other (D). Over subjects, each hue pair served equally often as $A$ and $B$, and as $C$ and $D$, and each hue was equally often associated with the richer of the two concurrent schedules.

The duration of each trial was $60 \mathrm{sec}$, and each trial was followed by a 10 -sec intertrial interval (ITI). A 1 -sec change-over delay prevented responses from being reinforced within $1 \mathrm{sec}$ of having pecked the alternative response key. Each session consisted of 32 trials. Each of the concurrent schedules was presented for 16 trials (randomly distributed) in each session. The data collected were number of responses, number of reinforcements, and time spent in the presence of each of the four stimuli. Time spent in the presence of a stimulus was measured from the first peck (or change-over peck) to that stimulus, to the first change-over peck to the alternative stimulus, or to the end of the trial, whichever came first.

Each pigeon was trained on this task for a minimum of nine sessions and until it reached a time-stability criterion. The timestability criterion was a range over the last three sessions of no more than $10 \%$ of the mean (over those same three sessions) of the time spent in the presence of that stimulus. Alternatively, performance was judged to be stable if the three-session range was no more than a total of $32 \mathrm{sec}$ ( $2 \mathrm{sec}$ per trial involving that stimulus). Either criterion had to be met for all four stimuli on the same three sessions. Training sessions were conducted 7 days a week.

Test 1. As each pigeon attained the stability criterion, it was tested on the next day. Test sessions were identical to training sessions with the following exceptions. Each test session included four 60 -sec test trials involving a choice between the B and D stimuli. No reinforcement was provided on test trials. Test 1 consisted of six test sessions.

Test 2. Six additional test sessions were conducted with the four test trials consisting of a choice between the $A$ and $C$ stimuli interspersed among the training trials. Once again, no reinforcement was provided on test trials.

Test 3. The pigeons were then divided into two groups (counterbalanced for hue associated with each of the schedules). Responding to the A stimulus was extinguished for pigeons in Group $A$ - and responding to the $C$ stimulus was extinguished for pigeons in Group C-. Extinction trials involved the presentation of a single stimulus for $60 \mathrm{sec}$ followed by a 10 -sec ITI. The single stimulus appeared on the left response key on half the trials and on the right key on the remaining trials. Single stimulus training continued for each pigeon for a minimum of 24 trials and until it reached an extinction criterion of three consecutive trials without a response. As each pigeon reached the extinction criterion, it was immediately given a test session involving $12 \mathrm{BD}$ probe trials of $60 \mathrm{sec}$ each, randomly interspersed among 24 additional singlestimulus extinction trials. No reinforcement was provided for responses during BD probe trials.

\section{RESULTS}

In all statistical analyses the .05 level of significance was adopted.

\section{Training}

Baseline performance on the two concurrent discriminations was averaged over the last three sessions of training. According to the matching law (Herrnstein, 1970), for the $A(V I 20 \mathrm{sec})$ versus $B(V I 80 \mathrm{sec})$ discrimination, the expected proportion of responses, time, and reinforcements in the presence of $B$ relative to total responses, time, and reinforcements is 20 . As can be seen in Figure 2 , the actual values were quite close to those of the prediction. Similarly, for the C(VI $40 \mathrm{sec}$ ) versus D(VI $80 \mathrm{sec})$ discrimination, the expected proportion of responses, time, and reinforcements in the presence of $D$ is .33 , and the actual values were quite close. Mean responses, time, and reinforcements in the presence of each of the training stimuli are presented in Table 3.

In addition, a prediction can be made for the relative rates of responding to, and time in the presence of, B ver- 


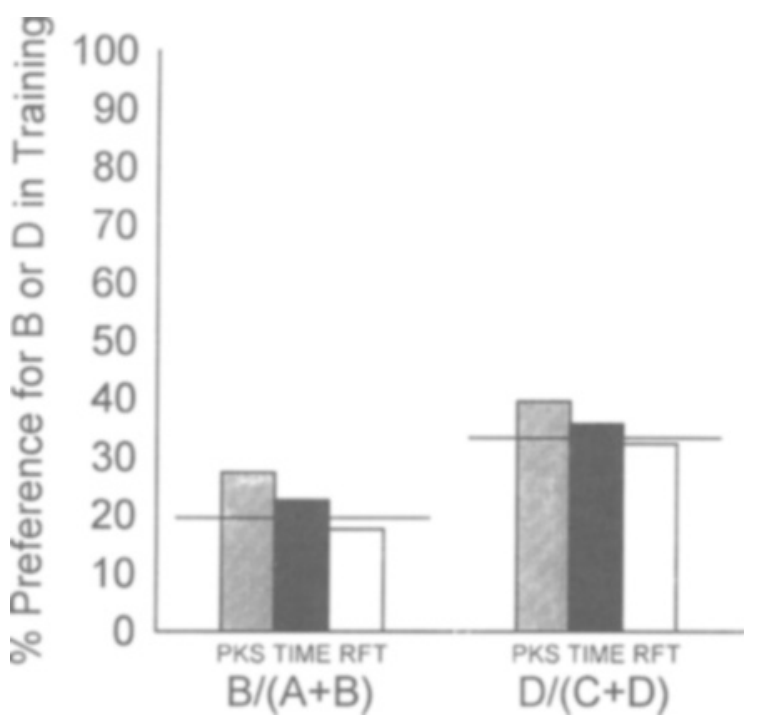

Figure 2. Percentage preference: keypeck responses (PKS), time spent, and reinforcements (RFT) in the presence of each of the two stimuli associated with a variable interval 80 -sec schedule of reinforcement ( $B$ and $D$ ), during the last three sessions of concurrent schedules training $\mid A(V I 20$ sec) vs. B(VI 80 sec) and C(VI $40 \mathrm{sec})$ vs. D(VI $80 \mathrm{sec})$ ]. The horizontal lines indicate the percentage preference for responses and time in training predicted for these schedules by the matching law $(20 \%$ for Stimulus $B$ trained in the $A B$ discrimination and $33 \%$ for $D$ trained in the $\mathrm{CD}$ discrimination).

sus D in training based solely on the schedules of reinforcement associated with those stimuli. First, the rates of responding in the presence of the $\mathrm{AB}$ and the $\mathrm{CD}$ discriminations were about the same (an average of 1.39 responses/sec in the presence of the $\mathrm{AB}$ discrimination and 1.44 responses $/ \mathrm{sec}$ in the presence of the $\mathrm{CD}$ discrimination). Second, because $20 \%$ of the responses in the $\mathrm{AB}$ discrimination were expected to occur to $\mathrm{B}$, and $33 \%$ of the responses in the $C D$ discrimination were expected to occur to $D$, the expected proportion of responses to $B$ to total responses to $B$ and $D$ was expected to be .377 . The actual proportion of responses to $B$ to total responses to $B$ and $D$ was .397. Similarly, the proportion of time in the presence of $B$ to time in the presence of $B$ and $D$ was

Table 3

Mean Responses, Reinforcements, and Time (in Seconds) in Presence of Each Stimulus Presented

During the Last Three Sessions of Training and During the First Session of Test

\begin{tabular}{cccc} 
& \multicolumn{3}{c}{ Mean } \\
\cline { 2 - 4 } Stimulus & Responses & Time & Reinforcements \\
\hline A & 981.1 & 43.4 & 720.5 \\
B & 351.4 & 9.3 & 210.4 \\
C & 813.2 & 21.1 & 599.4 \\
D & 541.6 & 10.1 & 332.4 \\
\hline
\end{tabular}

Note-Maximum time in the presence of a stimulus pair was $960 \mathrm{sec}$ however, the times for each stimulus pair do not sum to $960 \mathrm{sec}$ because, on each trial, time from the onset of the stimulus pair to the first response was not assigned to either stimulus.
391. Both proportions were significantly smaller than $.500[F(1,7)=15.07$ and 25.93 , respectively $]$. Thus, if the proportion of responses to, and time in the presence of, $B$ versus $D$ on probe trials is affected by the learned pattern of responding in training, one would expect a preference for D over B (of .623 based on the expected relative schedules of reinforcement, .603 based on calculated response rates in training, or .609 based on calculated time in training). Similarly, if preference on BD probe trials is determined by contrast experienced during training, $\mathrm{D}$ should be preferred over $B$ because $B$ was presented with a stimulus (A) that was associated with a more contrasting schedule (VI $20 \mathrm{sec}$ ) than was D (presented with a stimulus, C, associated with a VI $40 \mathrm{sec}$ schedule).

\section{Test 1}

On the 1 st day of test with $B$ versus $D$ probe trials, a clear preference for $B$ was found using either proportion of responses made to $B$ or proportion of time spent in the presence of $B$. The Test 1 data from the 1 st day of test appear in Figure 3, and mean responses and time in the presence of each of the test stimuli appear in Table 4.

Two-way mixed repeated measures analyses of variance (ANOVAs) performed on the probe-trial preference scores from the 1st day of test (with hue pair as the second factor) indicated that there were significantly more responses to $\mathrm{B}$ than to $\mathrm{D}[F(1,7)=33.11]$ and significantly more time was spent in the presence of $B$ than $D$ $[F(1,7)=44.71]$.

Although the preference for B over D was somewhat reduced when the data were pooled over the six test sessions because responding was extinguished during the probe trials, analyses indicated that a significant preference for B remained for both responses $(.656)[F(1,7)=$ $13.70]$ and time $(.644)[F(1,7)=8.41]$. By the last $\mathrm{BD}$ test session, the preference for $B$ had dropped to .443 for responses and .519 for time.

\section{Test 2}

Although one might argue that responding on $\mathrm{AC}$ probe-trial tests might be affected by the prior $B D$ probetrial tests, test sessions with $\mathrm{AC}$ probe trials were included as a manipulation check. As can be seen in Figure 3, on the first test session, a clear preference for $\mathrm{A}$ over $\mathrm{C}$ was found on these probe trials. According to the matching law, relative responses and time in the presence of $A$ [given A(VI $20 \mathrm{sec}$ ) vs. C(VI $40 \mathrm{sec})$ ] should have been .67. According to the pattern of responding acquired in training, however, $80 \%$ of the responses (and time) in the $\mathrm{AB}$ discrimination should have been to $\mathrm{A}$, whereas $67 \%$ of the responses (and time) in the CD discrimination should have been to $C$. Thus, according to this analysis, the relative proportion of responses (and time) to $\mathrm{A}$ versus $\mathrm{C}$ would be predicted to be .544 . The actual preference for $A$ on the first test session (.746 for responses and .727 for time) was closer to that predicted by the schedules themselves (see also Williams, 1993; Williams \& Royalty, 1989). Thus, responding on AC probe trials 
appeared to be unaffected by schedule interactions. The Test 2 data from the 1st day of test appear in Figure 3, and mean responses and time in the presence of the test stimuli appear in Table 4.

Two-way mixed repeated measures ANOVAs performed on the first session of $\mathrm{AC}$ probe trials indicated that there was a significant preference for $\mathrm{A}$ in both responses $[F(1,7)=21.24]$ and time $[F(1,7)=18.06]$. The preference for $\mathrm{A}$ over $\mathrm{C}$ was not significantly different from the levels predicted by the matching law (.667), however $[F(1,7)=2.01$ and 1.97 for responses and time, respectively].

Preference analyses performed on the AC probe-trial data pooled over all six test sessions failed to yield significant differences in either responses $[F(1,7)=1.81]$ (preference for A was .595) or time $(F<1)$ (preference for A was .551). Apparently, the high density of reinforcement associated with both $\mathrm{A}$ and $\mathrm{C}$ during training allowed for rapid learning about the change in contingency associated with the novel $\mathrm{AC}$ probe trials. By the last $\mathrm{AC}$ test session, the preference for $\mathrm{A}$ over $\mathrm{C}$ had dropped to .488 for responses and .444 for time.

\section{Test 3}

Responding reached the extinction criterion in an average of 37.8 trials for pigeons for which responding to

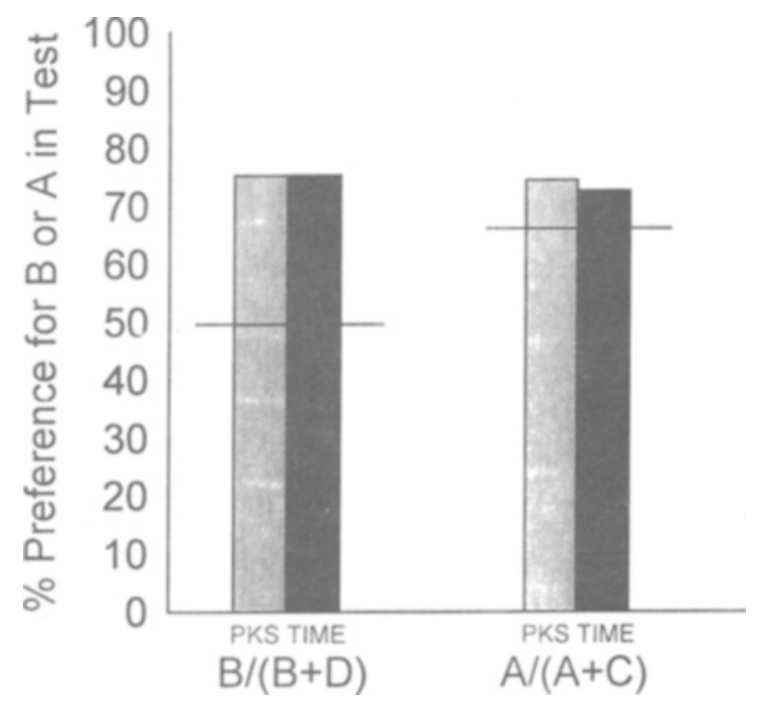

Figure 3. Test 1-probe-trial data from the first session of the $B$ versus $D$ test (on the left): proportions of keypeck responses (PKS), and time spent in the presence of $B$, paired in training with the richer variable interval (VI) schedule of reinforcement $A$, relative to those measures from $D$, paired in training with the leaner VI schedule of reinforcement $C$. Test 2-probe data from the first session of the $A$ versus $C$ test (on the right): proportions of keypeck responses, and time spent in the presence of $A$, associated in training with the richest VI schedule of reinforcement, relative to those measures from $\mathrm{C}$, the stimulus associated with the richer schedule from the other concurrent schedule of reinforcement. The horizontal lines indicate the proportion of responses and time in training predicted by the matching law $(50 \%$ preference for $B$ on the B vs. D trials, $67 \%$ preference for $A$ on the A vs. C trials).
Table 4

\begin{tabular}{lrr}
\multicolumn{3}{c}{$\begin{array}{c}\text { Mean Responses and Time (in Seconds) in Presence of } \\
\text { Each Stimulus Presented During } \\
\text { the First Session of Each Test }\end{array}$} \\
\cline { 2 - 3 } & \multicolumn{2}{c}{ Mean } \\
\hline & Responses & Time \\
\hline & & \\
Stimulus & 257.6 & 167.8 \\
D & 86.9 & 55.0 \\
& & \\
A & 274.5 & 171.3 \\
C & 80.3 & 64.4 \\
& & \\
Group A- & & 232.5 \\
B & 119.0 & 240.8 \\
D & 74.5 & 351.8 \\
Group C- & & 174.7 \\
B & 365.5 & \\
D & 165.0 & \\
\hline
\end{tabular}

Note-The times for each stimulus pair do not sum to the total time because, on each trial, time from the onset of the stimulus pair to the first response was not assigned to either stimulus.

the A stimulus was extinguished and in an average of 42.5 trials for pigeons for which responding to the $\mathrm{C}$ stimulus was extinguished. Following extinction of $\mathrm{A}$, there was a substantial drop in preference for the B stimulus (to .378 for pecks and .476 for time) on BD test trials. In contrast, following extinction of $\mathrm{C}$, the preference for $\mathrm{B}$ was quite high (.681 for pecks and .656 for time). The Test 3 data from the lst day of test appear in Figure 4 and mean responses and time in the presence of each of the test stimuli appear in Table 4.

Recall that at the end of Test 1 , the pigeons showed virtually no differential preference for B over D. A twoway ANOVA performed on responses on $B D$ probe trials on Test 3, with group and hue pair as factors, indicated that the preference for $\mathrm{B}$ was significantly greater for pigeons in Group $\mathrm{C}$ - than for pigeons in Group $\mathrm{A}-[F(1,4)=$ 13.90]. A similar analysis performed on the time data indicated that the effect of group approached, but did not reach, statistical significance $[F(1,4)=5.17]$.

\section{DISCUSSION}

The results of the present study are consistent with neither a contrast account nor an account based on the response patterns acquired during training. The results are consistent, however, with value transfer theory. In spite of the lower level of responding to (and time spent in the presence of) $B$ relative to $D$ in training, a clear preference for B over D was found on probe trials in test. According to value transfer theory, more value should transfer from a stimulus associated with a high density of reinforcement, $A$, to its accompanying stimulus, $B$, than should transfer from a stimulus associated with a medium density of reinforcement, $\mathrm{C}$, to its accompanying stimulus, $\mathrm{D}$.

The results of the present study indicate that value transfer can occur in a free-operant concurrent schedules 


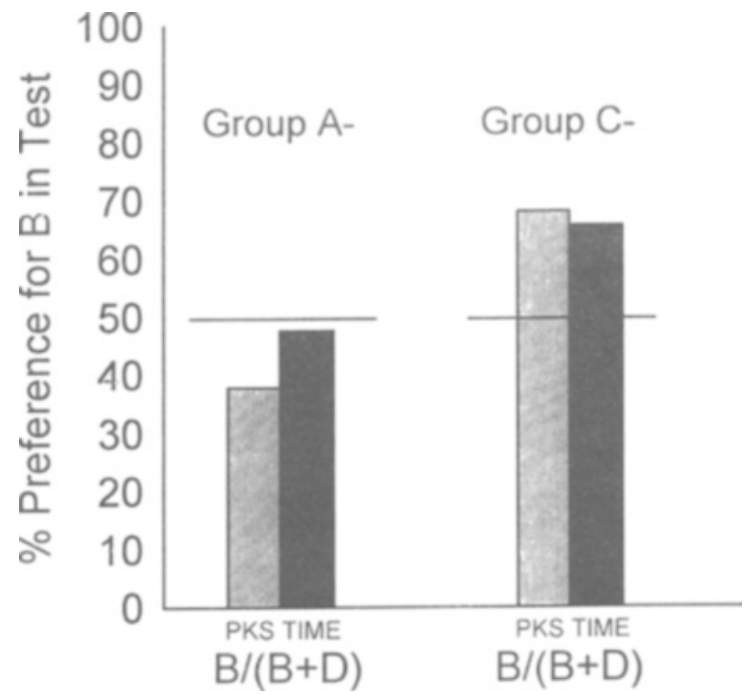

Figure 4. Test 3-data from the B versus $D$ test session: proportions of keypeck responses (PKS), and time spent in the presence of $B$, paired in training with the richer variable interval (VI) schedule of reinforcement $A$, relative to those measures from $D$, paired in training with the leaner VI schedule of reinforcement $C$, following devaluation of either $A$ (Group $A-$, on the left) or $C$ (Group $\mathrm{C}-$, on the right). The horizontal lines indicate the proportion of responses and time in training predicted by the matching law (50\% preference for B on the B vs. D trials) for both groups.

discrimination, and that the transfer of value from a richer to a poorer schedule does not depend on the poorer schedule being extinction. Thus, it appears that neither the free-operant procedure nor reinforcement associated with poorer schedules was responsible for the contrastlike effects found by Belke (1992). Instead, it would appear that in Belke's experiment, in which the pigeons acquired two concurrent discriminations [A(VI $20 \mathrm{sec})$ vs. $\mathrm{B}(\mathrm{VI} 40 \mathrm{sec})$ and $\mathrm{C}(\mathrm{VI} 40 \mathrm{sec})$ vs. D(VI $80 \mathrm{sec})$ ], the relative response patterns acquired in training (i.e., to respond primarily to $A$ rather than to $B$, and to $C$ rather than to D) were primarily responsible for the pigeons' preference for $\mathrm{C}$ over $\mathrm{B}$ on probe trials.

On the other hand, although there were large differences in the response patterns acquired to the two stimuli associated with VI 40-sec schedules (B and C) in Belke's experiment, some aspects of his data might be viewed as evidence for value transfer. The proportion of responses made to B in training (see Belke, 1992, Figure 1a) was consistently higher than the proportion of time spent in the presence of that stimulus. As estimated from Belke's figure, the proportion of relative responding to $B(.44)$ to relative time spent in the presence of $B(.33)$ was 1.33 . However, one would expect this value to be no greater than 1.0 (i.e., equal to or less than the rate of pecking A). Thus, consistent with the hypothesized transfer of value from $\mathrm{A}$ to $\mathrm{B}$, the rate of pecking $\mathrm{B}$ was higher than one would expect $[F(1,3)=35.53$ (estimated)]. In contrast, the proportion of responses made to $\mathrm{C}$ in training was consistently lower than the proportion of time spent in the presence of that stimulus. The proportion of relative responding to $\mathrm{C}(.56)$ to relative time spent in the presence of D (.70) was .82 (again, estimated from Belke's Figure 1a). Thus, consistent with the hypothesized transfer of value from $C$ to $D$, the rate of pecking $D$ was higher than one would expect, or conversely, the rate of pecking $\mathrm{C}$ was (marginally) lower than one would expect $[F(1,3)=$ 9.48 (estimated)].

Although the response patterns acquired in training cannot account for the preference for $B$ over $D$ found on probe trials in the present experiment, Zentall and Sherburne (1994) have argued that differential experiences with $B$ and $D$ in training could have contributed to the preference for $B$ that they found in their discrete-trial simultaneous-discrimination procedure (involving $\mathrm{A}+\mathrm{B}-$ and $C \pm D-$ ). Zentall and Sherburne reasoned that the higher density of reinforcement associated in training with their A stimulus (as compared with their $\mathrm{C}$ stimulus) might have resulted in fewer errors made to $B$ than to $D$. Fewer errors to $B$ than to $D$ could have resulted in the development of less inhibition to $B$, and thus to a preference for B over D. However, Zentall and Sherburne failed to find support for such an account in their experiment. Not only did they fail to find a significant difference in errors made to B versus D in training, but they also failed to find a positive correlation between the $B$ to $D$ ratio of errors in training and the preference for $B$ over $D$ on probe trials.

A similar argument can be raised with regard to the present experiment. Because it was found that significantly more responses were made to (and time was spent in the presence of) $D$ than $B$ in training, and because the rate of reinforcement is relatively insensitive to those variables in the context of VI schedules, it would be expected that the number of reinforcements per peck or the local rate of reinforcement would be greater to $B$ than to $D$. In fact, reinforcements per peck during the last three training sessions were significantly greater to $\mathrm{B}(.028)$ than they were to $\mathrm{D}(.020)[F(1,7)=9.95]$. Similarly, reinforcements $/$ second were significantly greater to $B(.045)$ than they were to $\mathrm{D}(.031)[F(1,7)=22.53]$.

If the relative rate of reinforcement did contribute to the preference for B over D on probe trials, however, it should have been apparent in the correlation between relative rate of reinforced responding to $B$ versus $D$ in training, and in the magnitude of $B$ versus $D$ preference on probe trials. Thus, those pigeons that showed the largest difference in local rate of reinforcement between $B$ and $D$ should also have shown the greatest preference for $B$ over $D$ in test. However, the correlation between relative reinforcement rate in training and preference for $\mathrm{B}$ over $\mathrm{D}$ on probe trials was negative (for responses, $r=-.29$, as well as for time, $r=-.30$ ), and neither was significantly different from zero.

Gibbon (1995) has recently developed a mathematical model to account for Belke's (1992) findings. Gibbon accepted the possibility that Belke's pigeons might have learned to spend twice as much time responding to $\mathrm{A}(\mathrm{VI} 20 \mathrm{sec})$ as to $\mathrm{B}(\mathrm{VI} 40 \mathrm{sec})$, and twice as much time 
responding to C(VI $40 \mathrm{sec})$ as to $\mathrm{D}(\mathrm{VI} 80 \mathrm{sec})$, but he also noted that such a bias, by itself, would account for only a 2 to 1 preference for C over B. Instead, Belke reported that his pigeons showed a 4 to 1 preference for $\mathrm{C}$ over B. To account for this ratio, Gibbon posited that when pigeons acquire this task, they are deciding continuously whether to stay with the stimulus they are currently pecking or to switch to the alternative. According to Meyerson and Meisen (1980), when pigeons are trained on concurrent schedules, the rate at which they decide whether to switch to the other schedule or not depends on the overall rate of reinforcement associated with the schedules. Thus, the better the overall rate of reinforcement, the more often the pigeons decide whether to stay or switch. Although it is not clear why the rate at which an animal decides whether to switch or stay should depend on the overall rate of reinforcement, rather than on the rate of reinforcement associated with the stimulus currently being pecked, this appears to be the case. In fact, Gibbon's assumption is quite consistent with value transfer theory because the theory provides a mechanism by which reinforced responding to one stimulus can affect the rate of switching away from a stimulus associated with a different schedule of reinforcement.

A second assumption of Gibbon's (1995) model is that the probability with which the pigeons decide to stay will depend on the relative probability of reinforcement associated with the two available schedules (i.e., the matching law). Gibbon's model can be represented as follows: The relative time spent in the presence of one of two training stimuli $=1 /[$ (the decision rate)(the probability of switching)]. If one calculates this value for each of two training stimuli ( $\mathrm{B}$ and $\mathrm{C}$ ), the ratio of the two values should indicate the preference for one over the other on test trials. Thus, during training in Belke's (1992) experiment, the pigeons learn to switch out of $B$ twice as often as they switch out of C. In addition, they decide about switching out of B twice as often as they do about switching out of $\mathrm{C}$. The combination of these two factors leads to the prediction that the pigeons spend four times as much time in the presence of $\mathrm{C}$ as they do in the presence of $B$.

Gibbon's (1995) model also makes an unusual prediction. In spite of the fact that the schedule associated with $A$ is twice as rich as the schedule associated with $C$, the model predicts that on $\mathrm{AC}$ probe trials, more time should be spent in the presence of $C$ than in the presence of $A$ ! This should be true because, even though the decision rule itself should be the same for the two stimuli (stay about twice as often as switch, because of the matching law), according to the model, the rate at which the pigeons decide about staying or switching in the presence of $A$ is twice as great as the rate in the presence of $\mathrm{C}$. Gibbon reported just such a finding.

When Gibbon's (1995) model is applied to the data from the present experiment, it does not do as well, however. According to the model, when a decision is made, pigeons should switch out of B(VI $80 \mathrm{sec}$ ) for A(VI $20 \mathrm{sec})$ four times out of five (4/5). Similarly, they should switch out of D(VI $80 \mathrm{sec})$ for C(VI $40 \mathrm{sec})$ two times out of three $(2 / 3)$. However, the decision rate (which is proportional to the overall reinforcement rate associated with each pair of concurrent schedules) in the presence of $\mathrm{A}(\mathrm{VI} 20 \mathrm{sec}) \mathrm{B}(\mathrm{VI}) 8 \mathrm{sec}$ ) should be $1 / 20 \mathrm{sec}+1 / 80 \mathrm{sec}=$ $5 / 80 \mathrm{sec}$, whereas the decision rate in the presence of C(VI $40 \mathrm{sec}) \mathrm{D}$ (VI $80 \mathrm{sec}$ ) should be $1 / 40 \mathrm{sec}+1 / 80 \mathrm{sec}=$ $3 / 80 \mathrm{sec}$. Thus, the relative time spent in the presence of $B$ should be $1 /(5 / 80 \mathrm{sec})(4 / 5)=20 \mathrm{sec}$, and the relative time spent in the presence of $D$ should be $1 /(3 / 80 \mathrm{sec})$ $(2 / 3)=40 \mathrm{sec}$. Therefore, according to Gibbon's model, on $\mathrm{BD}$ probe trials, pigeons in the present experiment should have spent twice as much time in the presence of $\mathrm{D}$ as they did in the presence of $\mathrm{B}$. According to the data, however, the reverse is true. Furthermore, $B$ was preferred over $D$ in spite of the fact that in training the pigeons spent less time in the presence of B(VI $80 \mathrm{sec})$ than they did in the presence of D(VI $80 \mathrm{sec}$ ). Thus, the effects of value transfer can be seen even though the response patterns acquired to the two stimuli were in the opposite direction (although they were considerably less biased than they were in Belke's, 1992, experiment).

The Test 2 (A vs. C test) data are also inconsistent with Gibbon's (1995) model. According to Gibbon, time spent in the presence of $\mathrm{A}$ should be proportional to 1/ [(decision rate in $A B)$ (probability of switching out of $A)$ ]. Recall that the decision rate is proportional to the overall rate of reinforcement in the presence of the stimulus pair. Thus, time spent in the presence of A should be 1/ $(5 / 80 \mathrm{sec})(1 / 5)$, or $80 \mathrm{sec}$. Similarly, time spent in the presence of $C$ should be proportional to $1 /[$ (decision rate in CD)(probability of switching out of C)]; therefore, time in $C$ should be $1 /(3 / 80 \mathrm{sec})(1 / 3)$, or $80 \mathrm{sec}$, as well. Thus, according to Gibbon's model, the pigeons should be indifferent between $\mathrm{A}$ and $\mathrm{C}$; however, a clear preference for A was found.

Although value transfer theory is strongly supported by the present results, it is insufficient to account for the preference for C over A reported by Gibbon (1995). According to value transfer theory, not only should $A(V I 20 \mathrm{sec})$ have more direct value than C(VI $40 \mathrm{sec})$, but also A(VI $20 \mathrm{sec}$ ) should benefit more (or suffer less) from the presence of $B(V I 40 \mathrm{sec})$ than $C(V I 40 \mathrm{sec})$ should benefit from the presence of $D(V I 80 \mathrm{sec})$. Similarly, the four-to-one preference for C over B found by both Belke (1992) and Gibbon (1995) is greater than the two-to-one preference that one would expect on the basis of the different response patterns trained. According to value transfer theory, the value transferred from A(VI $20 \mathrm{sec}$ ) to $B(V I 40 \mathrm{sec})$ would be expected to decrease, rather than increase, the preference for C over B. Thus, to account for all the data, it may be that Gibbon's rate-of-switchingduring-acquisition parameter does, in fact, play a role in probe-trial preference tests.

The results of the devaluation phase of the present experiment offer support for a second-order conditioning account of the value transfer effect. Pigeons for which responding to $C(V I 40 \mathrm{sec})$ was extinguished maintained their preference for $B$, whereas those for 
which responding to $A(V I 20 \mathrm{sec})$ was extinguished reversed their preference [i.e., they showed a preference for $\mathrm{D}$ (VI $80 \mathrm{sec})]$. Thus, the stimulus associated with the poorer schedule appears to have become a signal for the presence of the stimulus associated with the richer schedule. When the signaled schedule changed, apparently, so did the value of the signal.

Earlier, it was proposed that what distinguishes contrast effects from value transfer effects is the use of successive discriminations rather than simultaneous discriminations in training. A closer examination of the literature reveals what appears to be an exception to this rule. Williams (1977) reported contrast effects in the acquisition of simultaneous discriminations. Williams first trained pigeons on a simultaneous hue discrimination. Responses to one hue were reinforced $100 \%$ of the time; responses to the other hue were never reinforced. Then for half of the pigeons, the probability of reinforcement associated with correct responses was reduced to .33 (Group .33), whereas for the remaining pigeons, the probability of reinforcement remained at 1.0 (Group 1.0). Finally, a second simultaneous discrimination involving shape stimuli was introduced, in which all correct responses were reinforced. Williams found that pigeons in Group .33 acquired the shape discrimination significantly faster than did pigeons in Group 1.0, and he interpreted this finding as a contrast effect. Whether this contrast effect is related to more traditional positive contrast effects found with multiple VI schedules (see, e.g., Reynolds, 1961) is not clear. In terms of comparison with the present findings, however, although training in Williams's experiment involved simultaneous discriminations, the relevant contrast effects occurred between stimuli presented successively.

\section{REFERENCES}

BELKE, T. W. (1992). Stimulus preference and the transitivity of preference. Animal Learning \& Behavior, 20, 401-406.

Fersen, L. von,, Wynne, C. D. L., Delius, J. D., \& Staddon, J. E. R.
(1991). Transitive inference formation in pigeons. Journal of Experimental Psychology: Animal Behavior Processes, 17, 334-341.

GiBBon, J. (1995). Dynamics of time matching: Arousal makes better seem worse. Psychonomic Bulletin \& Review, 2, 208-215.

Guttman, A., Sutterer, J. R., \& Brush, F. R. (1975). Positive and negative behavioral contrast in the rat. Journal of the Experimental Analysis of Behavior, 23, 377-383.

HEARST, E. (1968). Discrimination learning as the summation of excitation and inhibition. Science, 162, 1303-1306.

Herrnstein, R. J. (1970). On the law of effect. Journal of the Experimental Analysis of Behavior, 13, 243-266.

LoGAN, F. A. (1966). Transfer of discrimination. Journal of Experimental Psychology, 71, 616-618.

MEyerson, J., \& MEISEN, F. M. (1980). The kinetics of choice: An operant systems analysis. Psychological Review, 87, 160-174.

REYNOLDS, G. S. (1961). Behavioral contrast. Journal of the Experimental Analysis of Behavior, 4, 57-71.

SPENCE, K. W. (1937). The differential response in animals to stimuli varying within a single dimension. Psychological Review, 44, 430444.

Steirn, J. N., Weaver, J. E., \& Zentall, T. R. (1995). Transitive inference in pigeons: Simplified procedures and a test of value transfer theory. Animal Learning \& Behavior, 23, 76-82.

WiLliams, B. A. (1977). Contrast effects in simultaneous discrimination learning. Animal Learning \& Behavior, 5, 47-50.

WiLliaMs, B. A. (1993). Molar versus local reinforcement probability as determinants of stimulus value. Journal of the Experimental Analysis of Behavior, 59, 163-172.

WILliams, B. A. (1994). The role of probability of reinforcement in models of choice. Psychological Review, 101, 704-707.

Williams, B. A., \& RoYALTY, P. (1989). A test of the melioration theory of matching. Journal of Experimental Psychology: Animal Behavior Processes, 15, 99-113.

Zentall, T. R., \& Sherburne, L. M. (1994). Transfer of value from $\mathrm{S}+$ to $\mathrm{S}-$ in a simultaneous discrimination. Journal of Experimental Psychology: Animal Behavior Processes, 20, 176-183.

Zentall, T. R., Sherburne, L. M., Roper, K. L., \& Kraemer, P. J. (1996). Value transfer in a simultaneous discrimination appears to result from within-event Pavlovian conditioning. Journal of Experimental Psychology: Animal Behavior Processes, 22, 68-75.
(Manuscript received July 29, 1995 ; revision accepted for publication January 13, 1996.) 